\title{
Per-rectal endoscopic myotomy (PREM) for pediatric Hirschsprung's disease
}

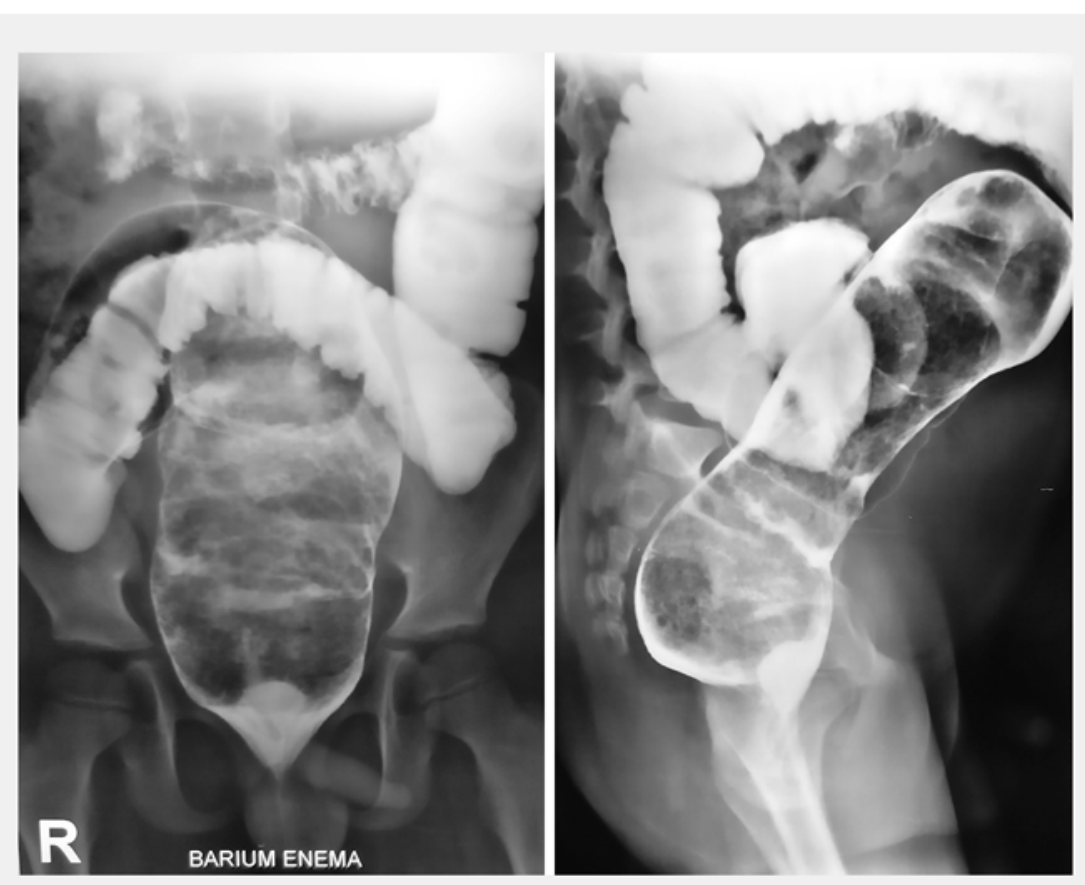

Fig. 1 Barium enema in an 8-year-old boy showing the characteristic signs of Hirschsprung's disease.

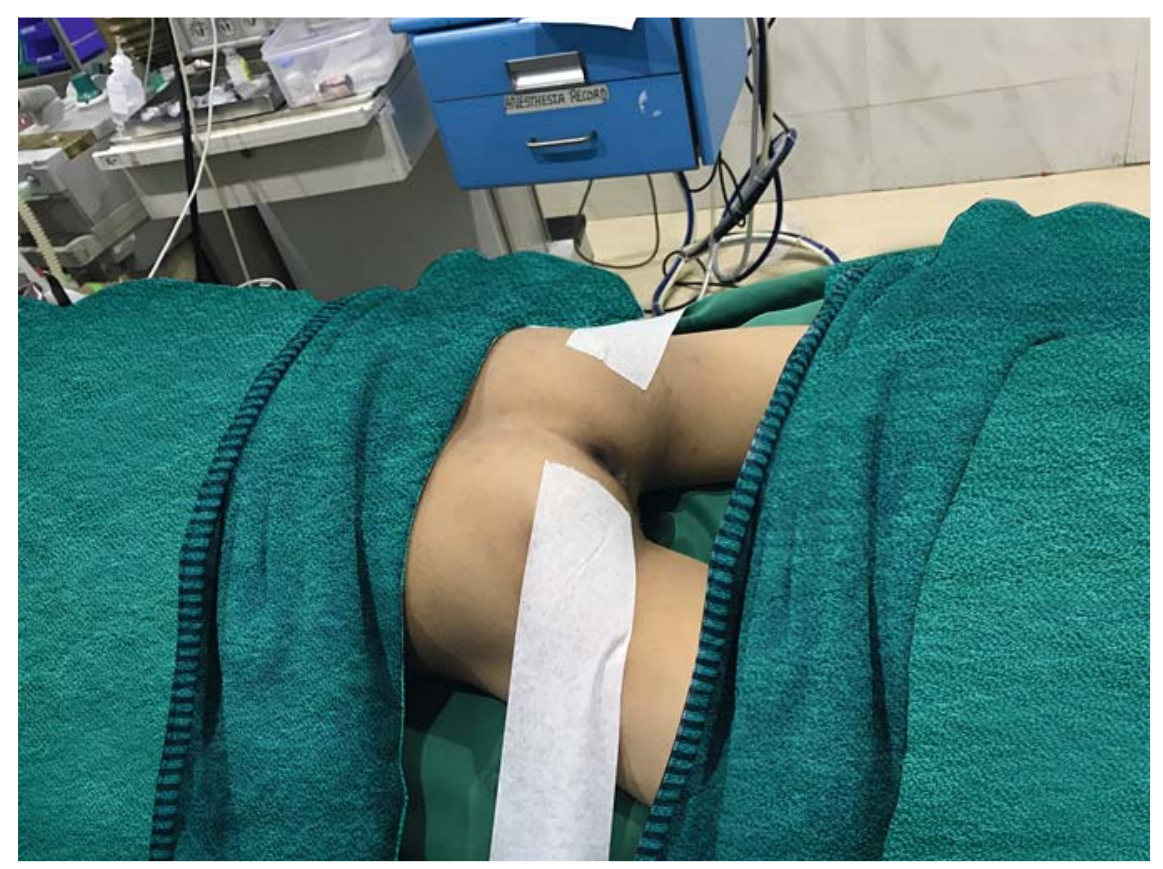

- Fig. 3 The patient is positioned for per-rectal endoscopic myotomy, in the prone position with the buttocks strapped laterally.

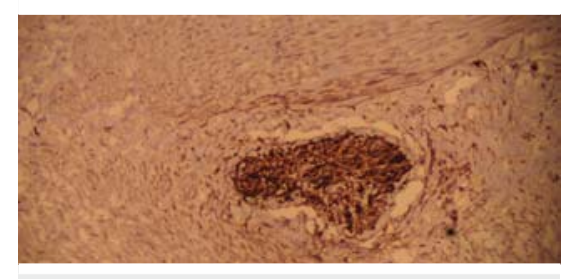

- Fig. 2 Biopsy taken from the rectum at $8 \mathrm{~cm}$ (magnification $\times 40$ ), stained immunohistochemically with 5100 , showing a nerve bundle and the absence of ganglion cells.

Hirschsprung's disease is a congenital disorder characterized by the absence of intrinsic ganglion cells in the myenteric plexuses of the hindgut. The majority of patients present during infancy or childhood with constipation, intestinal obstruction, or megacolon [1]. Standard treatment includes single- or multi-stage pull-through surgery [2]. We have previously reported per-rectal endoscopic myotomy (PREM) for adult Hirschsprung's disease [3]. The rationale of this is to disrupt the spastic bowel segments, like those in achalasia or pylorospasm are disrupted by peroral endoscopic myotomy (POEM) or pyloromyotomy (G-POEM) [4,5]. This report describes the technique and outcome of PREM in a pediatric patient with Hirschsprung's disease.

An 8-year-old boy had had refractory constipation since the neonatal period that was partially relieved by high-dose laxatives. Barium enema demonstrated a spastic rectum and dilated sigmoid colon, which were classical of Hirschsprung's disease ( $\mathbf{F i g} \mathbf{1}$ ). Colonoscopy showed a spastic non-distensible empty rectum and dilated sigmoid colon with stool residue. Deep mucosal biopsies demonstrated ganglion cells at $8 \mathrm{~cm}$ but these were absent distally ( $\triangleright$ Fig. 2). Manometry demonstrated absent rectoanal inhibitory reflex (RAIR).

Given our previous experience, we obtained consent for PREM from the patient's parents. PREM was performed 

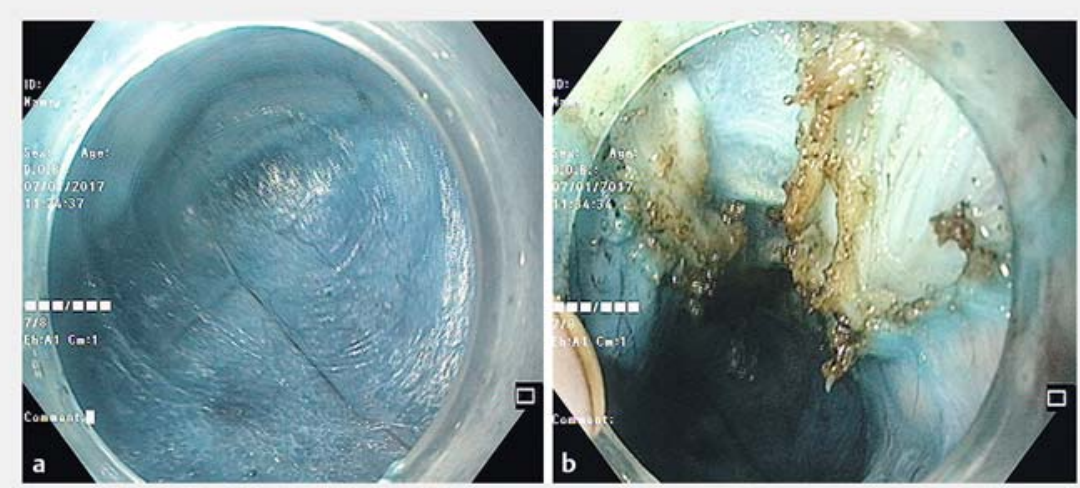

- Fig. 4 Endoscopic images during per-rectal endoscopic myotomy showing: a the completed submucosal tunnel (note the muscle layer at the 12 o'clock indicating posterior myotomy in the prone position); $\mathbf{b}$ the completed full-thickness myotomy (note the divided muscle fibers at the 12 o'clock position).
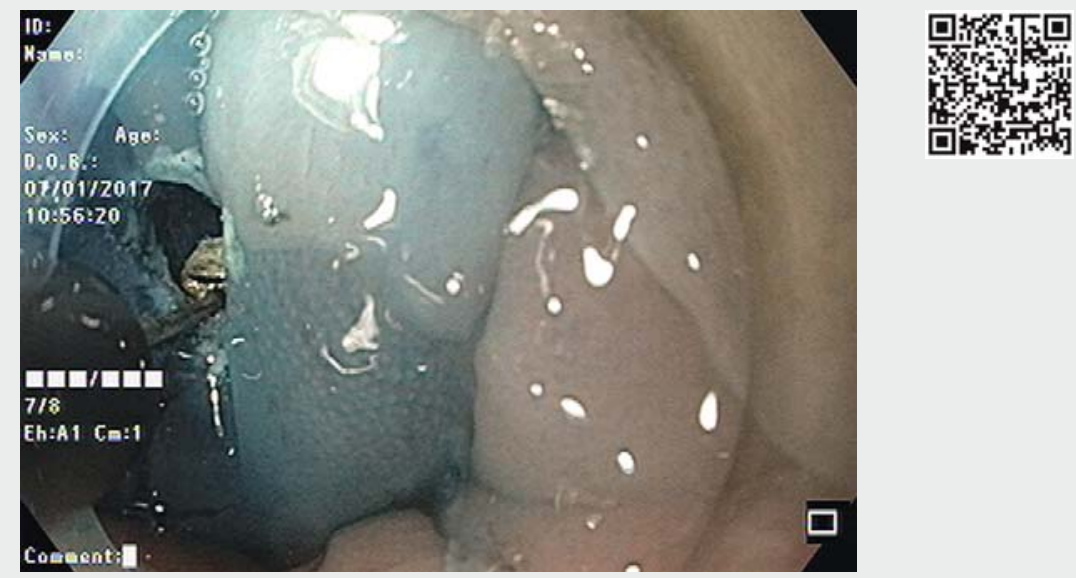

$\checkmark$ Video 1 The technique of per-rectal endoscopic myotomy (PREM). After a mucosal incision is made inside the dentate line, a $10-\mathrm{cm}$ submucosal tunnel is created. Full-thickness posterior myotomy is performed, stopping short of the anorectal junction. The mucosa is closed using endoclips.

with the patient under general anesthesia and in the prone position ( $\triangleright$ Fig.3). A full-thickness posterior myotomy was performed, starting inside the anorectal junction and extending $10 \mathrm{~cm}$ proximally, using the technique described in our earlier report [3] ( Fig.4; > Video 1 ). The patient was fasted for 12 hours and oral liquids were started thereafter. His first bowel movement was recorded at 28 hours. Intravenous antibiotics were continued for 48 hours. He was discharged on the 4th post-procedure day on oral lactulose $15 \mathrm{~mL}$ twice daily. At follow up after 2 weeks, the patient re- ported passing one to two semisolid soft stools per day while taking $15 \mathrm{~mL}$ lactulose daily. No episodes of incontinence or enterocolitis were reported. Sigmoidoscopy in an unprepared colon showed mucosal healing and the presence of rectal stool. The current duration of followup is 48 weeks and to date the patient remains well.

Endoscopy_UCTN_Code_TTT_1AQ_2AF
Competing interests

None

The authors

Amol Bapaye ${ }^{1}$, Tarun Bharadwaj', Mahesh Mahadik ${ }^{1}$, Sandeep Ware ${ }^{1}$, Pankaj Nemade ${ }^{1}$, Rajendra Pujari ${ }^{1}$, Jay Bapaye ${ }^{1,2}$

1 Shivanand Desai Center for Digestive Disorders, Deenanath Mangeshkar Hospital and Research Center, Pune, India

2 Smt. Kashibai Navale Medical College, Pune, India

Corresponding author

\section{Amol Bapaye, MD}

Shivanand Desai Center for Digestive Disorders, Deenanath Mangeshkar Hospital and Research Center, Pune 411004, India amolbapaye@gmail.com

References

[1] Wyllie R. Motility disorders and Hirschsprung Disease. In: Kliegman R, Behrman R, Jenson H, Stanton B, eds. Nelson Textbook of Pediatrics. Philadelphia, PA: Saunders Elsevier; 18th edn. 2008: 1565-1567

[2] Sharma S, Gupta DK. Hirschsprung's disease presenting beyond infancy: surgical options and postoperative outcome. Pediatr Surg Int 2012; 28: 5-8

[3] Bapaye A, Wagholikar G, Jog S et al. Per rectal endoscopic myotomy for the treatment of adult Hirschsprung's disease: First human case (with video). Dig Endosc 2016; 28 : $680-684$

[4] Inoue H, Santi EG, Onimaru M et al. Submucosal endoscopy: from ESD to POEM and beyond. Gastrointest Endosc Clin North Am 2014; 24: $257-264$

[5] Khashab MA, Ngamruengphong S, CarrLocke D et al. Gastric per-oral endoscopic myotomy for refractory gastroparesis: results from the first multicenter study on endoscopic pyloromyotomy (with video). Gastrointest Endosc 2017; 85: 123 - 128

\section{Bibliography}

DOI https://doi.org/10.1055/a-0583-7570

Published online: 22.3.2018

Endoscopy 2018; 50: 644-645

(c) Georg Thieme Verlag KG

Stuttgart · New York

ISSN 0013-726X 


\section{CORRECTION}

Bapaye A, Bharadwaj T, Mahadik M et al. Per-rectal endoscopic myotomy

(PREM) for pediatric Hirschsprung's

disease.

Endoscopy 2018, 50:

doi:10.1055/a-0583-7570

In the above mentioned article the page numbers have been corrected.

This was corrected in the online version on August 17, 2018. 